\title{
FORMAL AND INFORMAL MACRO-REGIONAL TRANSPORT CLUSTERS AS A PRIMARY STEP IN THE DESIGN AND IMPLEMENTATION OF CLUSTER-BASED STRATEGIES
}

\author{
Olga Nežerenko ${ }^{1}$, Ott Koppel ${ }^{2}$ \\ ${ }^{1}$ Department of Business Administration, Tallinn School of Economics and Business Administration, \\ Tallinn University of Technology \\ Tallinn, 12618, Akadeemia tee 3, Estonia \\ Phone: +3725264686, e-mail: olga.nezerenko@gmail.com \\ ${ }^{2}$ Department of Logistics and Transport, Faculty of Civil Engineering, Tallinn University of Technology \\ Tallinn 12616, Akadeemia tee 15a, Estonia \\ Phone: +3726202605, e-mail: ott.koppel@ttu.ee
}

\begin{abstract}
The aim of the study is the identification of a formal macro-regional transport and logistics cluster and its development trends on a macro-regional level in 2007-2011 by means of the hierarchical cluster analysis. The central approach of the study is based on two concepts: 1) the concept of formal and informal macro-regions, and 2) the concept of clustering which is based on the similarities shared by the countries of a macro-region and tightly related to the concept of macro-region. The authors seek to answer the question whether the formation of a formal transport cluster could provide the BSR a stable competitive position in the global transportation and logistics market.
\end{abstract}

Keywords: Baltic Sea Region (BSR), hierarchical cluster analysis (statistics), location quotient, macro-region, transport and logistics

\section{Introduction}

Regionalisation and globalisation tendencies have brought about the expansion of new forms of active economic integration on the macro-regional level, among these new forms there is also the macroregional concept for regional development (EC, 2013, 2).

The intensification of international cooperation within the Baltic Sea Region (BSR) started with the launching of the European Union Strategy for the Baltic Sea Region in early 2009. Numerous projects and clusters (StarDust, SmartComp, Transbaltic, etc.) dealing with regional growth helped to achieve a certain level of coordination and complementarity across the countries around the Baltic Sea.

The purpose of this paper is to examine the potential of the BSR for formal cluster development in distribution, maritime and transport and logistics sectors (transport and logistics field) on the macroregional level. The urgency of the topic is conditioned by the fact that the driven clustering process within macro-regional cooperation shifts the BSR towards becoming a virtual macro-region formation. Macroregional policy, in its turn, tends to be associated with the identification of macro-regional clusters, which provide a basis for the development of informal forms of cooperation (Herrschel, 2009, 280). Thus, the central approach of the study is based on two concepts.

- The concept of formal (bounded) and informal (virtual) macro-regions.

- The concept of cluster, which is based on the similarities shared by the countries of a macroregion and tightly related to the concept of macro-region.

The authors examine the BSR as a virtual macro-region (which is informal and noninstitutionalized), established through the shared cluster policy objectives, and try to answer the main question of the research - can the formation of a formal transport cluster provide the BSR a stable competitive position in the global transport and logistics market? Kabashkin (2014) points out that in order to establish a region as a key component in global logistics networks, it is necessary to envision the strategic positioning of the region within the context of the overall global logistics networks.

The study is based on the cluster approach as an analytical tool of the BSR macro-regional policy for the transport and logistics (T\&L) field for the identification of its formal and informal nature. In the authors' opinion, the process of informal clustering prevails in today's macro-regional cooperation. Informal clustering implies realisation of macro-regional projects on the level of collaboration only among business partners. On the one hand, this applied strategic clustering approach contributes to the creation of 
a competitive business environment, while on the other hand, it may affect the competitiveness (as well as quality) of the macro-regional T\&L system as an international supply chain - the supply chain is as strong as its weakest link. The involvement of countries in international projects varies within the region (Finland, Sweden and Baltic Sea Germany are the most active countries in contrast to Norway and Baltic Sea Russia). Thus, one of the problems of cluster approach is concentration on well-performing regions (Dümmler and Thierstein, 2002, 11). Another tendency is the formation of new clusters, which eliminates the use of present regional resources.

As it can be seen, the concept of "cluster" is tightly related to the concept of "macro-region", which is based on the similarities shared by the countries of the region. Below, the authors provide a brief review of literature on clusters and establish some general concepts.

\section{Previous studies}

In recent years, regional economic integration has been given a fresh impetus in specialised literature and academic publications. Numerous papers are devoted to the outcomes of the "two-dimensional" regional economic policy, namely to (1) regional economic integration at the national level (Boronenko and Zaibote, 2011; Ivanov, 2009; Magomedov, 2011 et al.); and (2) regional economic integration at the international (macro-regional) level (Bialasiewicz et al., 2013; Garanti et al., 2014; Hettne and Söderbaum, 2000; Dubois et al., 2009 and others). The particularity of the macro-region lies in the character of international cooperation, which can be simplified, for example, through the countries' membership in a certain regional grouping or, vice versa, it can be complicated in case of its absence (i.e. the Baltic Sea, the Danube, the Adriatic and Ionian regions). The quality of engagement in the collaboration process may vary significantly as, according to the gravity model of trade, the presence of physical border can significantly limit the international business activity.

Bialasiewicz et al. (2013) examine European macro-regional policies as a threshold in between internal territorial cooperation and external cross-border cooperation, which goes beyond the EU external borders and engages its closest neighbourhood. The authors of the paper have adopted some basic principles of regional cooperation and applied these to macro-regional cooperation.

Herrschel (2009) studies the formal and informal nature of regions and highlights that business clusterings are informal because they are largely a personality-based form of cooperation, which may be potentially dangerous. Herrschel names at least three reasons why it may be so: (1) it has an informal character, which (2) as a rule is time-limited, and (3) it tends to be outside the government hierarchy.

On the basis of these approaches, the BSR's active business clustering policy is of informal character. The region relies on the distribution of the network participants within numerous clusters, which are often episodic in character (StarDust, SmartComp, Transbaltic, etc.). The regions based on this type of clustering policy can be considered non-institutionalised or informal; they are brought together through the shared policy objectives.

A formal region (as well as cluster) is based on a state's rigid regulation; it has a fixed structure and territory. In the authors' opinion, a formal T\&L macro-cluster is of major importance in the creation of a competitive macro-regional cluster of formal character. Herrschel (2009) has shown that formal and informal regions can produce negotiated, relatively stable and effective relationships.

Macro-regional/international clusters have been successfully established in the maritime sector. Wijnolst et al. (2003) discuss the need of creating a continent-wide cluster in the EU maritime sector, assuming that the maritime sector in Europe might benefit from this organisational form. Macro-regional maritime clusters are in many respects forerunners, especially in environmental technologies. These clusters also share common challenges, such as increasing production and labour costs, a combination of which could bring competitive advantage for the whole region in the future (Karvonen, 2012; Laaksonen and Mäkinen, 2012, 101). Contrary to the maritime sector, railway (due to territorial and infrastructural limitations) and especially road transport lack macro-regional clustering experience - the cluster policy in road transport and logistics is mainly implemented at the national level (Taina, 2012; Laaksonen and Mäkinen, 2012; Nežerenko et al., 2015).

As to Russian research experience, Ivanov (2009) has examined macro-regions as a functional area of the international economic integration at the macro- and mega-regional levels of the global economic system, which contributes to the formation of countries into aggregation and/or international clusters, which share common geo-economic and geo-strategic interests as well as resources, which lead to a favourable development of the international trade and business. Logistics cluster holds a special place in the cluster structures. Magomedov (2014) has sought to study the nature of the logistics cluster and compared it with the logistics system. The analysis shows that the signs of the cluster and the logistics system are almost 
identical. Magomedov has pointed out that the formation of other clusters depends on the logistics cluster development and that in regional clustering (logistic integration of territories), the development of transport infrastructure is determinative.

Analysis of the literature shows that regional economies (implemented at national or international levels) can achieve practical benefits by employing the concept of clusters (Boronenko and Zaibote, 2011; Garanti et al., 2014). The authors suggest that in order to provide a stable competitive position of the BSR in the global T\&L market, the formal and informal character of macro-region must coincide.

\section{Methodology}

The geographical coverage of the study is the BSR, which consists of eight EU countries and two non-EU countries: Denmark, Estonia, Finland, Baltic Sea Germany (BSG), Latvia, Lithuania, Baltic Sea Poland (BSP), Sweden, Norway and Baltic Sea Russia (BSR).

The methodological and practical contribution of the research lies in identifying the development dynamics of the BSR's T\&L field towards a formal macro-regional cluster with the help of HCA on the basis of a 'Specialisation' criterion. The authors suggest that identification of formal clusters of countries may increase the efficiency of the policy-making process in T\&L and give further macro-regional development a proper direction. The research structure is presented below (Fig. 1).

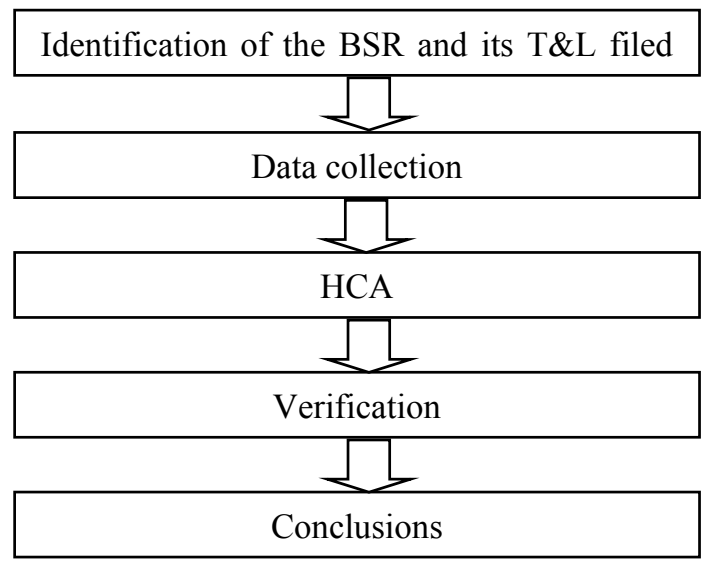

Figure 1. Research structure

Within the paper the authors use the term "clustering" in two meanings: (1) clustering as a way of collaboration in macro-regional projects and (2) clustering as a statistical technique.

Jucevicius and Puidokas (2007), Stejskal (2011), Danjko and Kuzenko (2012), Garanti and ZvirbuleBērzina (2013) analyse the application of methods for cluster identification. The most widespread method is the input-output analysis, which due to the limited statistical data turns out to be unsuitable for current research. In practice, the measurement of the clusters' performance is a very complicated task because the data necessary for the analysis of the various variables influencing the performance of a cluster are not always available (Prause, 2014).

The methodology used for the analysis of the BSR as a macro-regional cluster is based on quantitative methods (statistical analysis, hierarchical cluster analysis).Statistical data on the cluster indicator "Specialisation" (known as Location Quotient, or LQ) have been collected from Cluster Observatory databases. LQ, can be calculated on the basis of different measures of economic activity. Cluster Observatory uses employment data for identifying regional clusters, comparing the proportion of employment in a cluster category of a region/country to the total employment in the same region/country to the proportion of the total European employment in the given cluster category to the total European employment. Thus LQ says that if a region is more specialised in a specific cluster category than the overall economy across all regions is likely to indicate that the economic effects of the regional cluster have been strong enough to attract related economic activity from other regions to this location, and that spill-overs and linkages will be stronger. (European Cluster Observatory)

There is considerable disagreement in scientific literature about the minimum LQ necessary to identify the specialisation of a region in the particular industry (Garanti and Zvirbule-Bērzina, 2013, 96). 
The authors follow the methodology of Cluster Observatory, according to which the measure needs to be at least 2 to conclude that the region/country is specialised in a certain sector.

The analysis covers the BSR's T\&L field, which consists of (1) distribution sector (wholesale and retail sale), (2) maritime sector (fishing, aquaculture, manufacture of cordages, tanks, containers, etc.), and (3) T\&L sector (land and water transport, shipbuilding, warehousing and storage, etc.). Taking into account that statistical data were not available for some countries, the time frame of the research are the years 20072011.

For the identification of formal micro-, meso- and single T\&L clusters, hierarchical cluster analysis (HCA) has been applied. The analysis was conducted by means of the SPSS software using Ward's method, which allows forming clusters on the basis of LQ dynamics (Z-scores of the real values were used within the HCA) as a criterion that minimises the total within-cluster variance.

Clustering is a widespread technique of analysis in regional studies, which helps to identify inequalities within macro-regions (Humphries, 2007, Hernández et al., 2009; Mimis, 2013; Nežerenko et $a l ., 2015)$. The idea of hierarchical clustering lies in the identification of each object initially as a single cluster (or, in this case, country). Then, in multiple iterations, the two nearest clusters are merged into a bigger one - a T\&L micro-cluster. Meso-clusters emerge at the second stage of HCA, when two adjacent micro-clusters merge into a bigger one. After a few iterations, the algorithm reaches the final cluster structure - a single T\&L cluster. Dissimilarities between countries are shown as dendrograms according to the number of steps in cluster formation.

The overlapping of the formal and the informal natures of the BSR has been determined by using comparative analysis.

\section{Findings}

The current research is partly based on a previous study by Nežerenko et al. (2015), which showed that "formal" clusters can be formed on the basis of handled cargo volumes by the BSR within road, rail and maritime sectors. In the present study, the authors expand the formal cluster formation technique on the indicator LQ used by the European Cluster Observatory (see Appendix) for ranking the regions' potential in the formation of clusters.

The figure below (Fig. 2) presents the average LQ in three sectors for 10 countries of the BSR in the period 2007-2011.

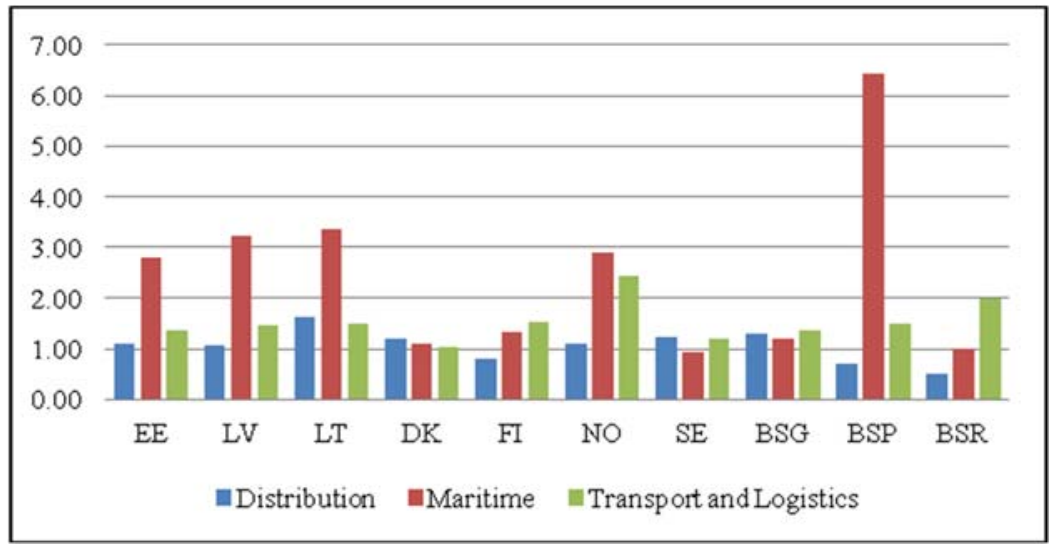

Figure 2. Average LQ in distribution, maritime and T\&L sectors for 10 countries of the BSR, 2007-2011

Source: European Cluster Observatory database

From the macro-regional perspective, the BSR demonstrates significant specialisation in maritime sector due to Baltic Sea Poland, Lithuania, Latvia, Norway and Estonia (their average LQ is 2.43). According to the mapping carried out in the course of the MarChain project, the maritime cluster of the BSR comprises the total of 11,900 companies with 211,500 employees (Karvonen and Heikkilä, 2013, 2). The second and the third places belong to T\&L and distribution sectors (with LQ of1.54 and 1.07, respectively).

The economic base theory argues that if the LQ for an industry is greater than 1 , it is assumed that the region exports the products from that industry. Distribution, maritime and T\&L sectors, in that respect, support the international trade of the BSR countries, which, in turn, can activate or, vice versa, restrain the 
BSR's transport and economic activity (Nežerenko et al., 2015). Considering that the T\&L field demonstrates the highest total number of employees, which is 2 million (Cluster Observatory) within all fields of economy in the region, it can be argued that it forms the economic basis of the BSR.

Further, the authors carry out HCA for mapping the dynamics of micro- and meso-clusters within T\&L field sectors.

\subsection{Distribution sector}

The distribution sector within and among micro-clusters formed at the first stage of HCA by Estonia, Norway and Latvia on the one hand, and Denmark, Sweden and Baltic Sea Germany on the other, demonstrates similarities in the dynamics of their development. These micro-clusters are separated by relatively high LQ and moderate tendencies of its fluctuations during the analysed period (Fig. 3).

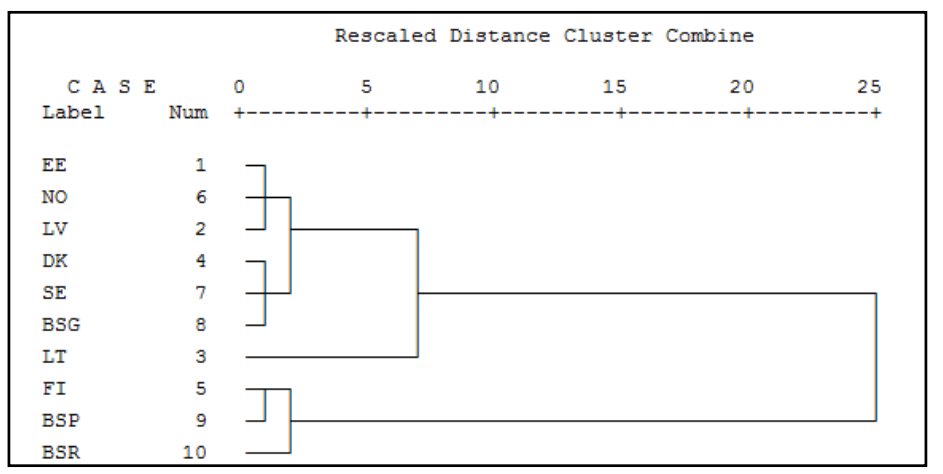

Figure 3. Dendrogram for the average LQ of the BSR distribution sector, 2007-2011(Transform values: Z-scores by case)

Source: The authors' calculations based on the European Cluster Observatory data

Lithuania does not compose any cluster at the earlier stages of the HCA. As shown in Figure 2, Lithuania demonstrates not only the highest LQ, but the highest rate of its positive dynamics in the BSR. The LQ of Finland and Baltic Sea Poland is too low, varying between 0.69 and 0.82 . At the first stage, Baltic Sea Russia becomes detached from all other countries with its LQ and also development dynamics, and joins the second weakest micro-cluster of Finland and Baltic Sea Poland at the second stage. In terms of meso-clusters, these countries show the modest potential of the sector development towards cluster specialisation.

\subsection{Maritime sector}

At the very first stage three clusters were formed (Fig. 4).

- The cluster of Sweden, Baltic Sea Russia, Denmark, Baltic Sea Germany and Finland.

- The cluster of Estonia, Norway, Latvia and Lithuania.

- The micro-cluster of Baltic Sea Poland.

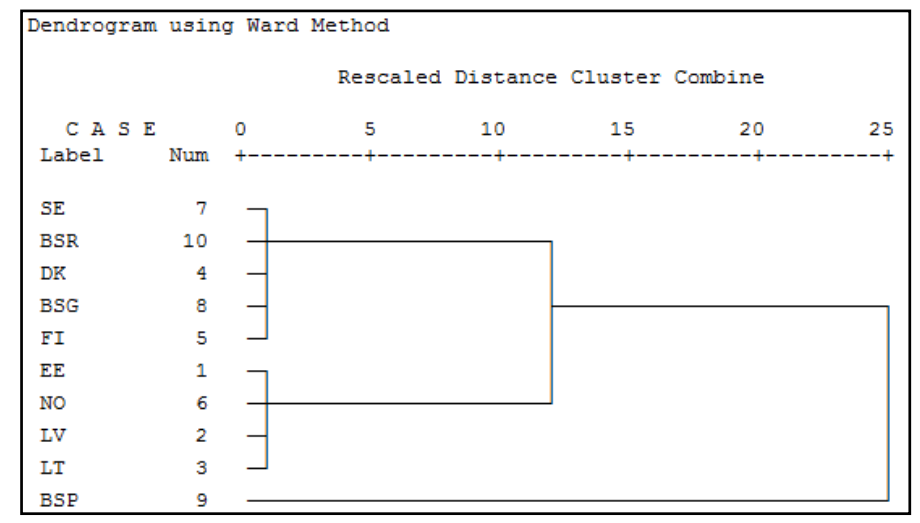

Figure 4. Dendrogram for average LQ of the BSR maritime sector, during 2007-2011 (Transform values: Z-scores by case) Source: The authors' calculations based on the European Cluster Observatory data 
A comparison of all three micro-clusters reveals that they demonstrate significant dissimilarities. Countries of the first micro-cluster have a relatively stable employment level during the periods of the crisis (2008-2009) and the post-crisis (2010-2011). In contrast, the second micro-cluster is more vulnerable, experiencing sharp falls and growth. Among the micro-cluster's countries, Lithuania and Estonia achieved better positions at the end of the analysed period, compared to their performance before the crisis. Despite the fact that Baltic Sea Poland has the highest LQ in the BSR, 6.43 (Fig. 2), it is dissimilar from other micro-clusters in that it is caused by the negative tendency in the employment sector up to 2010 (the loss is about 1 point). Only in 2011 did the positive dynamics lead to a negligible growth in LQ.

\subsection{Transport \&Logistics sector}

In terms of the transport and logistics sector, four micro-clusters have been formed (Fig.5).

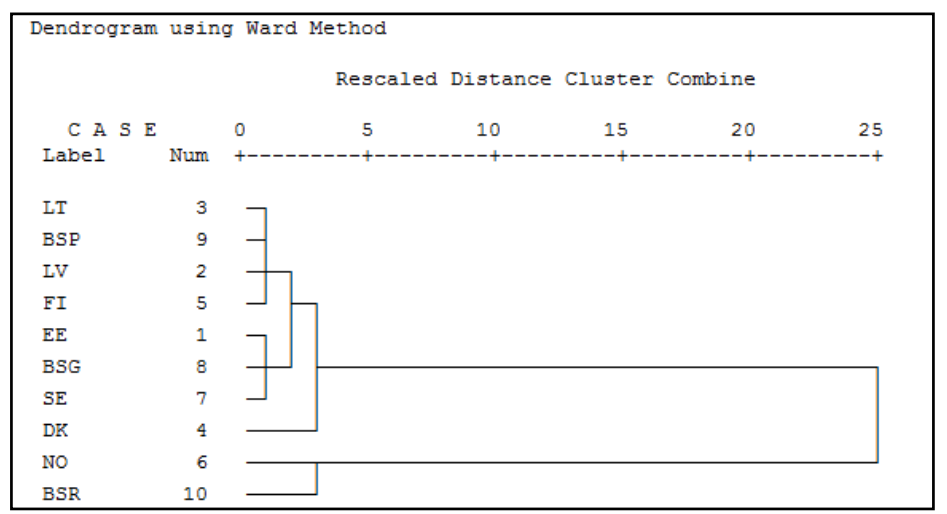

Figure 5. Dendrogram for average LQ of the BSR T\&L sector, 2007-2011(Transform values: Z-scores by case)

Source: The authors' calculations based on the European Cluster Observatory data

Countries of the first micro-cluster (Lithuania, Baltic Sea Poland, Latvia and Finland) demonstrate moderate grow of LQ, with the exception of Baltic Sea Poland, whose employment market was hit hard during the crisis. Despite the fact that Estonia, Baltic Sea Germany and Sweden comprise one micro-cluster, some differences in their LQ dynamics can be noticed. Namely, Estonia's LQ was growing during 20072011, leaving behind Sweden and Baltic Sea Germany, which could not improve their LQ after achieving the minimum meaning in 2010. Denmark formed a cluster on its own and joined two first-mentioned microclusters at the third stage of HCA, demonstrating confident stability. Two non-EU members - Norway and Baltic Sea Russia - form the fourth micro-cluster with a high level of dissimilarity relative to other microclusters due to the fact that starting from 2008 the dynamics of LQ was positive, thus the proportion of employment in the cluster category remained at the same level.

\subsection{Potential for the development of the Transport \&Logistics field}

Next, the authors examined the potential for the development of T\&L field (Fig.6).

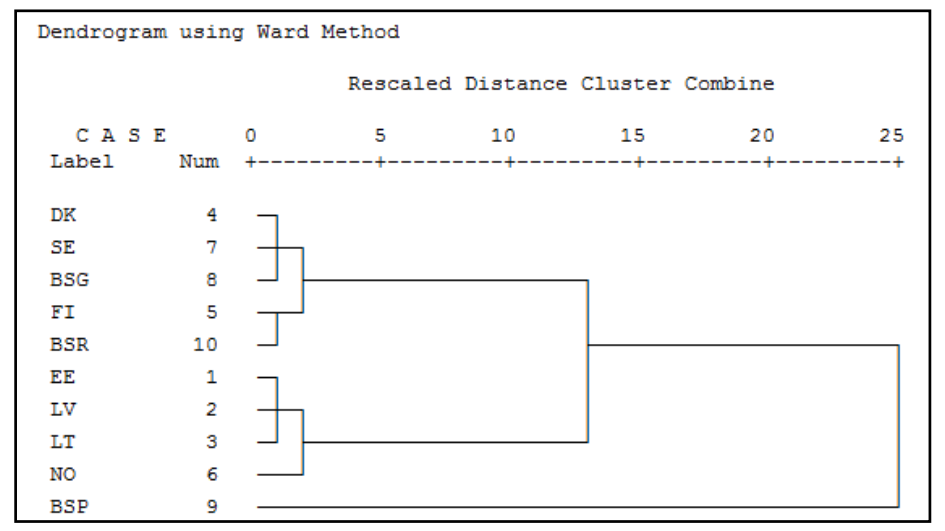

Figure 6. Dynamics for average LQ of the BSR's T\&L field, 2007-2011 (Transform values: Z-scores by case)

Source: The authors' calculations based on the European Cluster Observatory data 
As a result of the HCA, four micro-clusters emerged featuring the following development dynamics of T\&L field.

- Denmark, Sweden and Baltic Sea Germany demonstrate moderate growth rates with average LQ of 1.18 in the analysed period.

- Finland and Baltic Sea Russia were significantly hit by the crisis and demonstrate slow rates of the recovery process. Average LQ in the analysed period was 1.20.

- Estonia, Latvia and Lithuania were not affected by the crisis and demonstrate relatively high rates of growth during the period. Average LQ in the analysed period was 1.95.

- Norway was the strongest micro-cluster with moderate, but stable growth rates. Average LQ in the analysed period was 2.1 .

\section{Verification of the Baltic Sea Region's potential toward formation of a formal single Transport \& Logistics macro-cluster}

National and intergovernmental initiatives are the basis of macro-regional cooperation and can be presented as umbrella projects which cover countries randomly, regardless of the countries' transport sector performances, LQ, and involvement in TEN-T corridors. Next, the authors take a look at the involvement of the BSR countries in eight transport projects, recently launched within the macro-regional T\&L policy (Fig. 7).

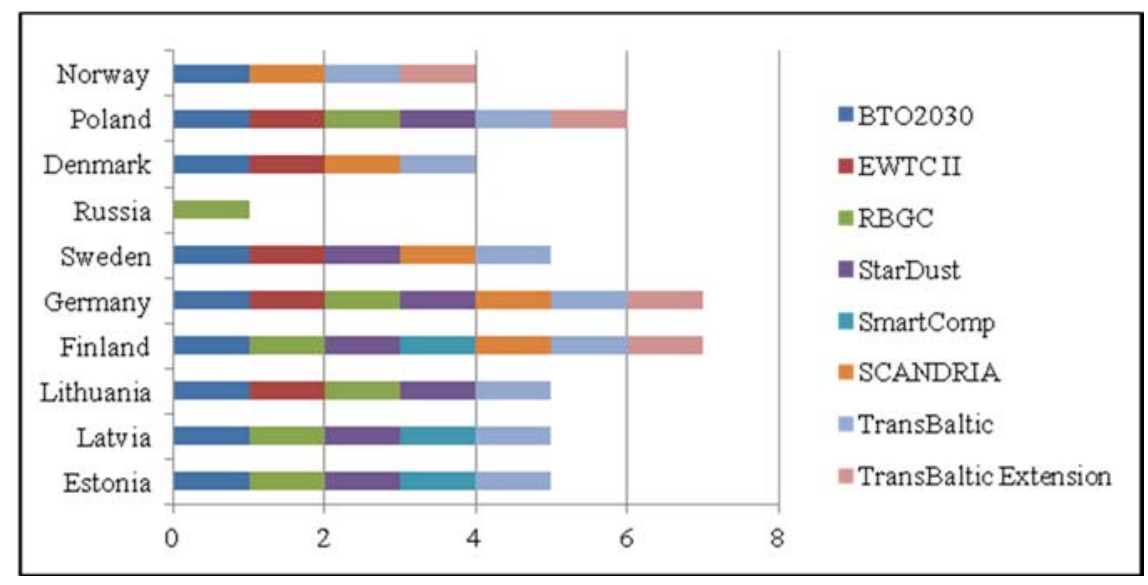

Figure 7. The BSR engagement in "informal" macro-regional cooperation in 2009-2013

Source: Compiled by the authors based on the Baltic Sea Region Programme 2007-2013 database

Baltic Sea Germany and Finland are most actively involved in the macro-regional cooperation. Baltic Sea Poland holds the second place; the third place is shared by Latvia, Lithuania and Sweden. Norway was involved only in two macro-regional projects, Russia only in one project - RBGC launched on the basis of TEN-T development. EWTC II and SCANDRIA are also TEN-T corridors, all together they cover practically the whole macro-region, and these projects tend to be formal. Other projects are informal business clusters initiated mainly in the maritime sector in the case of which the involvement of countries is lower.

The BSR transport field depends on three factors: (1) international trade; (2) production in industry and (3) sufficient investments in road and rail infrastructure (Nežerenko et al., 2015). These three attributes must be the focus of the macro-regional cluster-policy priorities. At the moment the maritime sector driven by Baltic Sea Poland, Lithuania, Latvia, Norway and Estonia has shown significant LQ-2.43.T\&L sector driven by Norway, Baltic Sea Russia and Finland has the LQ of 1.54. Road and rail transport, warehousing and storages and other components need an impulse to ensure diversified development towards a single T\&L cluster.

\section{Conclusions}

In this study, the authors have sought to make a theoretical contribution to the literature by continuing Herrschel's (2009) discussion concerning the concepts of formal and informal regions and 
clusters. The authors consider that the formal BSR is already bounded and demonstrates potential for the development of its T\&L field on the basis of its natural/formal comparative advantages, the accumulation and effective use of which is of great importance for providing the sustainable development of the region in the global context.

In the study three components of the BSR T\&L field (distribution, maritime and T\&L sectors) has been analysed from the perspective of formal macro-regional cluster formation on the bases of specialisation criterion. The results of the study confirm the viability of the assumption that the formal and informal clusters can coincide.

The maritime sector of the BSR has attributes of both formal and informal clusters. The high macroregional specialisation ratio coupled with intensive macro-regional business-cooperation form a stable competitive position of the BSR in the global maritime sector. In contrast to the maritime sector, the distribution sector tends to be the weakest component of the BSR T\&L field. Its development depends mainly on the business projects of a national character, but still it does not provide the required potential for national and macro-cluster formation as well (with the exception of Lithuania). In its turn, the T\&L sector goes beyond national borders, covering all transport modes, warehousing and storage. The BSR demonstrates positive dynamics in the formation of macro-regional cluster, but more intensive macroregional collaboration is required - the clustering experience varies significantly not only between national countries but between modes of transport and national transport systems unified into international transport corridors.

\section{References}

1. Baltic Sea Region Programme 2007-2013. Approved Projects. Database.

2. Bialasiewicz, L., Giaccaria, P., Jones, A. and Minca, C. (2013) Re-scaling 'EU'rope: EU macroregional fantasies in the Mediterranean. European Urban and Regional Studies, 20(1), 59-76. DOI: 10.1177/0969776412463372.

3. Boronenko, V. and Zeibote, Z. (2011) The Potential of Cluster Development and The Role of Cluster Support Policies in Latvia. Economic Annals, LVI (191), 35-67. DOI: 10.2298/EKA1191035B.

4. Cluster observatory. (2015) Clusters at your fingertips. Cluster mapping.

5. Dubois, A., Hedin, S., Schmitt, P. and Sterling, J. (2009) EU macro-regions and macro-regional strategies - A scoping study. Nordregio Working Paper, 4.

6. Dümmler, P. and Thierstein, A. (2002) The European Metropolitan Region of Zurich - A cluster of economic clusters? In: ERSA Conference, 2002, Dortmund.

7. EC. (2013) Report from the Commission to the European Parliament, the Council, the European Economic and Social Committee and the Committee of the Regions. European Commission. Brussels, 27.6.2013. COM (2013) 468 final.

8. Garanti Z. and Zvirbule-Berzina, A. (2013) In search for regional clusters in Latvia. Journal of Business Management, 7, 93-10.

9. Garanti, Z., Zvirbule-Berzina, A. and Yesilada, T. (2014) Cluster concept in policy planning documents: the cases of Latvia and Northern Cyprus. Verslas: Teorijairpraktika/Business: Theory and Practice, 15(2), 129-139. DOI: 10.3846/btp.2014.13.

10. Hernández, L., Ramos, R. and Ramos, S. (2009) Macro-regions and micro-regional inequalities: the European Union and the cohesion funds. UNU-CRIS Working Papers, 1.

11. Herrschel, T. (2009) A view from Europe and North America. International Journal of Public Sector Management, 22(3), 272-285. DOI: 10.1108/09513550910949244.

12. Hettne, B. and Söderbaum, F. (2000) Theorising the Rise of Regionness. New Political Economy, 5(3), 457-472. DOI: $10.1080 / 713687778$.

13. Humphries, A.S., Towriss, J. and Wilding, R. (2007) A taxonomy of highly interdependent, supply chain relationships. The International Journal of Logistics Management, 18(3), 385-40. DOI: 10.1108/09574090710835129.

14. Jucevicius. G. and Puidokas, M. (2007) Methodologies for analyzing the industrial clusters in the Baltic Sea region: a critical overview. Ekonomika ir vadyba, 12.

15. Kabashkin, I. (2012) Freight transport logistics in the Baltic Sea Region. Regional aspects. Transport and Telecommunication, 13(1), 33-50. DOI: 10.2478/v10244-012-0004-x.

16. Karvonen, T. and Heikkilä, A. (Eds). (2013) Maritime Clusters in the Baltic Sea Region: Estonia, Finland, Germany, Latvia, Lithuania, Poland and Sweden. Available from Internet: http://www.bsrstars.se/wp-content/uploads/2013/10/Maritime-Clusters-in-the-Baltic-Sea-Regionfinal.pdf. 
17. Laaksonen, E. and Mäkinen, H. (2012) The competitiveness of the Maritime Clusters in the Baltic Sea Region: Key Challenges from the Finnish Perspective. Journal of East-West Business, 19, 91-104. DOI:10.1080/10669868.2013.780502.

18. Mimis, A. and Georgiadis, T. (2013) Economic clustering of countries in the Asia-Pacific region. International Journal of Social Economics, 40(4), 355 - 366.

19. Nežerenko, O., Koppel, O. and Tuisk, T. (2015) Cluster approach in organization of transportation in the Baltic Sea Region. Transport. Article in press. DOI:10.3846/16484142.2014.994225.

20. Prause, G. (2014) Sustainable Development of Logistics Clusters in Green Transport Corridors. Journal of Security and Sustainability Issues, 4(1), 59-68. DOI: 10.2478/bjes-2014-0001.

21. Stejskal, J. (2011) Analysis of the applicability of selected methods for industrial clusters identifying. International journal of systems applications, engineering \& development, 3(5), 255-262.

22. Taina, J. (2012) A recorded interview at the Pan-European Institute, Turku School of Economics, University of Turku, September 12, 2012.

23. Wijnolst, N., Jenssen, J.I. and Sødal, S. (2003) European Maritime Clusters: Global Trends, Theoretical Framework, The Cases of Norway and the Netherlands. Policy Recommendation. The Netherlands: DUP Satellite.

24. Иванов, А. (2009) Внешнеэкономическая деятельность макрорегиона: теоретические аспекты исследования. Вестник Волгоградского государственного университета, 1(14), 51-56.

25. Данько, Т. and Куценко, Е. (2012) Основные подходы к выявлению кластеров в экономике региона. Проблемы современной экономики, 1, 248-254.

26. Магомедов, А. (2014) Логистика кластерных структур региональной экономики. Современные проблемы науки и образования, 4. 


\section{Appendix}

"Specialisation" criterions of the BSR countries in Distribution, Maritime and Transport \& Logistics sectors

\begin{tabular}{|c|c|c|c|c|c|}
\hline Country & 2007 & 2008 & 2009 & 2010 & 2011 \\
\hline \multicolumn{6}{|l|}{ Distribution } \\
\hline Estonia & 1.17 & 1.23 & 1.07 & 1.07 & 1.07 \\
\hline Latvia & 1.11 & 1.06 & 1.06 & 1.09 & 1.10 \\
\hline Lithuania & 1.47 & 1.49 & 1.70 & 1.73 & 1.73 \\
\hline Baltic Sea Poland & 0.74 & 0.73 & 0.69 & 0.71 & 0.71 \\
\hline Baltic Sea Germany & 1.41 & 1.30 & 1.31 & 1.27 & 1.29 \\
\hline Denmark & 1.20 & 1.17 & 1.18 & 1.18 & 1.25 \\
\hline Norway & 0.75 & 1.21 & 1.20 & 1.22 & 1.22 \\
\hline Sweden & 1.20 & 1.17 & 1.20 & 1.34 & 1.34 \\
\hline Finland & 0.82 & 0.76 & 0.78 & 0.81 & 0.81 \\
\hline Baltic Sea Russia & 0.46 & 0.50 & 0.50 & 0.51 & 0.51 \\
\hline \multicolumn{6}{|l|}{ Maritime } \\
\hline Estonia & 2.62 & 2.43 & 2.59 & 3.15 & 3.18 \\
\hline Latvia & 3.49 & 3.17 & 2.98 & 3.24 & 3.27 \\
\hline Lithuania & 3.18 & 2.94 & 3.23 & 3.68 & 3.71 \\
\hline Baltic Sea Poland & 6.99 & 6.41 & 6.38 & 6.15 & 6.20 \\
\hline Baltic Sea Germany & 1.23 & 1.25 & 1.21 & 1.20 & 1.18 \\
\hline Denmark & 1.36 & 1.14 & 1.00 & 1.01 & 1.02 \\
\hline Norway & 3.15 & 2.72 & 2.79 & 2.90 & 2.92 \\
\hline Sweden & 1.01 & 0.93 & 0.89 & 0.93 & 0.94 \\
\hline Finland & 1.62 & 1.43 & 1.21 & 1.20 & 1.21 \\
\hline Baltic Sea Russia & 1.08 & 1.03 & 0.99 & 1.00 & 1.01 \\
\hline \multicolumn{6}{|l|}{ Transport \& Logistics } \\
\hline Estonia & 1.25 & 1.24 & 1.37 & 1.48 & 1.48 \\
\hline Latvia & 1.05 & 1.46 & 1.58 & 1.66 & 1.66 \\
\hline Lithuania & 1.18 & 1.45 & 1.68 & 1.57 & 1.57 \\
\hline Baltic Sea Poland & 1.95 & 1.92 & 1.30 & 1.14 & 1.14 \\
\hline Baltic Sea Germany & 1.23 & 1.46 & 1.48 & 1.38 & 1.35 \\
\hline Denmark & 1.04 & 1.03 & 1.03 & 1.04 & 1.04 \\
\hline Norway & 3.15 & 2.72 & 2.79 & 2.90 & 2.92 \\
\hline Sweden & 1.33 & 1.16 & 1.21 & 1.20 & 1.20 \\
\hline Finland & 1.50 & 1.56 & 1.52 & 1.58 & 1.58 \\
\hline Baltic Sea Russia & 2.16 & 1.93 & 1.95 & 1.97 & 1.97 \\
\hline
\end{tabular}

